\title{
Hubungan Kadar Hematokrit dan Tekanan Darah pada Subjek Laki-laki Perokok Usia Dewasa Muda
}

\author{
${ }^{1}$ Roi O. Isa \\ ${ }^{2}$ Linda W. A. Rotty \\ ${ }^{2}$ Efata B. I. Polii
}
${ }^{1}$ Program Studi Pendidikan Dokter Fakultas Kedokteran Universitas Sam Ratulangi Manado
${ }^{2}$ Bagian Ilmu Penyakit Dalam Fakultas Kedokteran Universitas Sam Ratulangi
Email: roiocricoisa@yahoo.com

\begin{abstract}
Smoking is a major health problem in Indonesia especially in adult males. The age of a person to initially start smoking becomes younger, therefore, the prevalence of smoking in Indonesia has increased in 2013 (36.3\%) compared to that in 2007 (34.2\%). Smoking is a risk factor for a number of chronic diseases such as cancer, lung diseases, and cardiovascular diseases. Several previous studies had suggested a relationship between hematocrit levels, blood viscosity and blood pressure. This study was aimed to determine the correlation between hematocrit level and blood pressure in young adult male smokers as subjects. This was an analytical study with a cross-sectional design. Blood pressure and hematocrit level were performed on a total of 40 male students of the Faculty of Engineering Sam Ratulangi University Manado. Data were analyzed statistically by using the Spearman correlation test. The correlation test on the relationship between blood hematocrit level and systolic blood pressure showed an $\mathrm{r}$ value of 0.236 and a $P$ value of 0.143 while the correlation test on the relationship between blood hematocrit level and diastolic blood pressure resulted in an $\mathrm{r}$ value of 0.352 and a $P$ value of 0.026 . Conclusion: There was a positive correlation between hematocrit level and diastolic blood pressure in young adult smokers but not for systolic blood pressure.
\end{abstract}

Keywords: smokers, hematocrit, blood pressure

\begin{abstract}
Abstrak: Merokok menjadi masalah kesehatan utama di Indonesia khususnya pada kaum lelaki dewasa. Usia seseorang mulai merokok semakin muda dan prevalensi merokok di Indonesia mengalami peningkatan pada tahun 2013 (36,3\%) dibandingkan tahun 2007 $(34,2 \%)$. Merokok sebagai faktor risiko sejumlah penyakit kronis seperti kanker, penyakit paru-paru, dan penyakit kardiovaskuler. Beberapa penelitian sebelumnya menyatakan adanya hubungan antara kadar hematokrit, viskositas darah, dan tekanan darah. Penelitian ini bertujuan untuk mengetahui hubungan kadar hematokrit dan tekanan darah pada subjek lakilaki perokok usia dewasa muda. Jenis penelitian ialah analitik dengan desain potong lintang. Subyek penelitian ialah 40 orang mahasiswa laki-laki Fakultas Teknik Universitas Sam Ratulangi Manado. Pemeriksaan tekanan darah dan hematokrit darah dilakukan terhadap seluruh subyek. Analisis statistik menggunakan uji korelasi Spearman. Hasil uji korelasi pada hubungan kadar hematokrit dengan tekanan darah sistolik (TDS) mendapatkan nilai $\mathrm{r}=0,236$ dan nilai $P=0,143$ sedangkan pada hubungan kadar hematokrit dengan tekanan darah diastolik (TDD) didapatkan nilai $\mathrm{r}=0,352$ dan nilai $P=0,026$. Simpulan: Terdapat hubungan positif antara kadar hematokrit dan tekanan darah diastolik pada perokok laki-laki usia dewasa muda tetapi tidak berlaku untuk tekanan darah sistolik.
\end{abstract}

Kata kunci: perokok, hematokrit, tekanan darah 
Merokok menjadi masalah kesehatan utama di Indonesia khususnya pada kaum lelaki dewasa. ${ }^{1,2}$ Diperkirakan sekitar 500 juta pengguna rokok di dunia akan meninggal akibat merokok. China menempati urutan pertama sebagai negara dengan penduduk perokok terbanyak di dunia kemudian diikuti oleh India dan Indonesia masingmasing di urutan kedua dan ketiga. ${ }^{3}$

Di Indonesia, perilaku merokok penduduk 15 tahun ke atas cenderung meningkat dari 34,2\% tahun 2007 menjadi 36,3\% tahun 2013. Dibandingkan dengan penelitian Global Adults Tobacco Survey (GATS) pada penduduk kelompok usia $\geq 15$ tahun, proporsi perokok laki-laki sebesar 67,0\% dan pada Riskesdas 2013 sebesar $64,9 \%$. Pada perempuan menurut GATS ialah 2,7\%, dan 2,1\% menurut Riskesdas 2013. Proporsi terbanyak perokok aktif setiap hari ialah kelompok umur 30-34 tahun yakni sebesar $33,4 \%$, pada laki-laki lebih banyak dibandingkan perokok perempuan $(47,5 \%$ banding $1,1 \%)$. Rerata jumlah keseluruhan rokok yang dihisap per hari mencapai 12,3 batang (13 batang untuk pria dan 8 batang untuk wanita), bervariasi dari yang terendah 9,9 batang di DI Yogyakarta dan tertinggi di Bangka Belitung sebesar 18,3 batang. Di Sulawesi Utara sendiri rerata jumlah batang rokok yang dihisap adalah sebesar 13,2 batang. ${ }^{4}$

Kebiasaan merokok merupakan salah satu faktor risiko hipertensi. Prevalensi hipertensi pada penduduk Indonesia usia 18 tahun ke atas pada tahun 2007 sebesar $31,7 \%$ sedangkan pada tahun 2013 sebesar $25,8 \%$. Komplikasi dari penyakit hipertensi yakni penyakit jantung koroner (PJK), gagal ginjal dan stroke. ${ }^{5}$

Studi yang dilakukan oleh Letcher et al. ${ }^{6}$ mendapatkan hubungan langsung antara tekanan darah, viskositas darah serta peningkatan hematokrit antara subjek normotensi dan hipertensi. Penelitian Cirillo et al. ${ }^{7}$ juga mendapatkan hubungan positif antara hematokrit, tekanan darah serta prevalensi tekanan darah pada 1.275 laki-laki dan 1.534 perempuan usia 25-74 tahun. $^{7}$

Penelitian ini bertujuan untuk menge- tahui hubungan kadar hematokrit dengan tekanan darah pada subjek pria perokok usia dewasa muda.

\section{METODE PENELITIAN}

Jenis penelitian ini ialah analitik dengan desain potong lintang pada 40 orang mahasiswa laki-laki di Fakultas Teknik Univesitas Sam Ratulangi Manado yang dilaksanakan pada bulan Oktober November 2017. Pemilihan sampel dilakukan berdasarkan kriteria inklusi dan eksklusi. Data diperoleh melalui kuesioner, kemudian dilakukan pemeriksaan tekanan darah dengan menggunakan sphygmomanometer merkuri standard dan pemeriksaan kadar hematokrit di laboratorium.

Data hasil penelitian dilakukan uji normalitas Shapiro-Wilk dan selanjutnya dilakukan uji korelasi Spearman kemudian disajikan dalam bentuk tabel dan grafik.

\section{HASIL PENELITIAN}

Tabel 1 memeperlihatkan karakteristik umum subyek penelitian. Didapatkan usia terendah 18 tahun dan tertinggi 24 tahun dengan rerata 20,32 serta nilai simpangan baku 1,803. Kadar hematokrit didapatkan nilai terendah $41 \%$ dan tertinggi $55 \%$ dengan rerata 49,61 serta nilai simpangan baku 3,2751. Nilai terendah tekanan darah sistolik (TDS) sebesar $110 \mathrm{mmHg}$ dan nilai tertinggi $140 \mathrm{mmHg}$ dengan rerata 122,75 serta nilai simpangan baku 6,4. Tekanan darah diastolik (TDD) didapatkan nilai terendah $70 \mathrm{mmHg}$ dan nilai tertinggi 100 mmHg dengan rerata 83,25 serta nilai simpangan baku 6,558.

Tabel 1. Karakteristik umum sampel penelitian

\begin{tabular}{lccccc}
\hline & N & Min. & Maks. & Mean & SD \\
\hline Usia & 40 & 18 & 24 & 20,32 & 1,803 \\
Hct $(\%)$ & 40 & 41 & 55 & 49,61 & 3,2751 \\
TDS & 40 & 110 & 140 & 122,75 & 6,4 \\
$(\mathrm{mmHg})$ & & & & & \\
$\begin{array}{l}\text { TDD } \\
(\mathrm{mmHg})\end{array}$ & 40 & 70 & 100 & 83,25 & 6,558 \\
\hline
\end{tabular}

Tabel 2 menunjukkan distribusi subjek berdasarkan lama merokok. Didapatkan sebanyak 2 orang (5\%) yang telah merokok 
selama 1 tahun, 24 orang $(60 \%)$ telah merokok selama 2-5 tahun, dan 14 orang $(35 \%)$ lainnya telah merokok selama >5 tahun.

Tabel 2. Distribusi lama merokok

\begin{tabular}{ccc}
\hline Lama merokok & $\mathbf{N}$ & $\mathbf{\%}$ \\
\hline 1 tahun & 2 & 5 \\
$2-5$ tahun & 24 & 60 \\
$>5$ tahun & 14 & 35 \\
Total & 40 & 100 \\
\hline
\end{tabular}

Tabel 3 menunjukkan distribusi subjek perokok berdasarkan klasifikasi perokok. Didapatkan sebanyak 17 subyek $(42,5 \%)$ yang merupakan perokok ringan, 19 subyek $(47,5 \%)$ merupakan perokok sedang, dan 4 subyek $(10 \%)$ merupakan perokok berat.

Tabel 3. Distribusi klasifikasi perokok

\begin{tabular}{ccc}
\hline Klasifikasi perokok & $\mathbf{N}$ & $\mathbf{\%}$ \\
\hline Ringan (<10 batang/hari) & 17 & 42,5 \\
Sedang (10-20 batang/hari) & 19 & 47,5 \\
Berat (>20 batang/hari) & 4 & 10 \\
Total & 40 & 100 \\
\hline
\end{tabular}

Pada tekanan darah sistolik dan tekanan darah diastolik, berdasarkan uji normalitas data mengunakan Shapiro-Wilk didapatkan nilai $P=0,000(<0,05)$ yang berarti distribusi data tidak normal (Tabel 4, Gambar 1).

Tabel 4. Hasil uji normalitas data Shapiro-Wilk

\begin{tabular}{cc}
\hline Variabel & Nilai Sig. $(\boldsymbol{P})$ \\
\hline TDS & 0,000 \\
TDD & 0,000 \\
\hline
\end{tabular}

Uji korelasi Spearman terhadap hubungan kadar hematokrit dan tekanan darah sistolik mendapatkan hubungan positif antara keduanya $(r=0,236)$ namun analisis statistik yang didapatkan tidak bermakna $(P=0,143)$ (Tabel 5).

Tabel 5. Hubungan kadar hematokrit dengan tekanan darah sistolik

\begin{tabular}{lccc}
\hline Variabel & N & $\begin{array}{l}\text { Spearman- } \\
\text { rho }\end{array}$ & $\boldsymbol{P}$ \\
\hline Hct-TDS & 40 & 0,236 & 0,143 \\
\hline
\end{tabular}

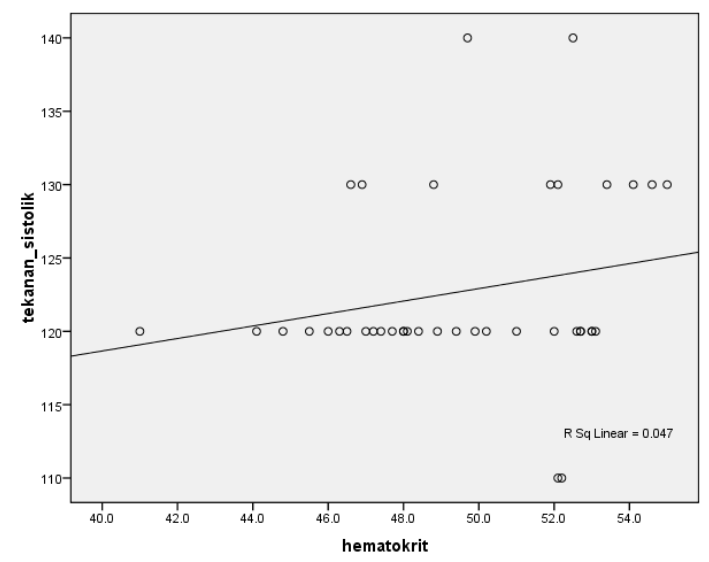

Gambar 1. Hubungan kadar hematokrit dan tekanan darah sistolik

Hubungan kadar hematokrit dan tekanan darah diastolik berdasarkan uji korelasi Spearman mendapatkan hubungan positif $(\mathrm{r}=0,352)$ yang bermakna $(P=0,026)$ antara keduanya dengan kecenderungan semakin tinggi kadar hematokrit maka semakin tekanana darah diastolik (Tabel 6, Gambar 2)).

Tabel 6. Hubungan kadar hematokrit dengan tekanan darah diastolik

\begin{tabular}{lccc}
\hline Variabel & $\mathbf{N}$ & $\begin{array}{c}\text { Spearman- } \\
\text { rho }\end{array}$ & p-value \\
\hline Hct-TDD & 40 & 0,352 & 0,026 \\
\hline
\end{tabular}

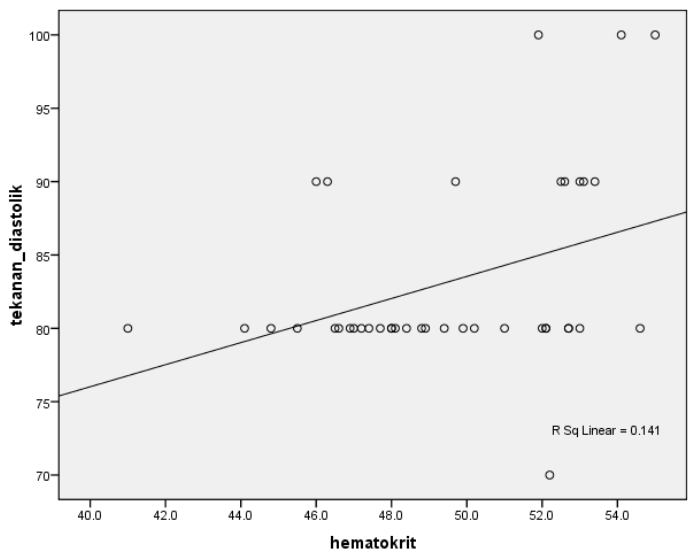

Gambar 2. Hubungan kadar hematokrit dengan tekanan darah diastolik

\section{BAHASAN}

Hasil penelitian ini menunjukkan adanya hubungan positif antara kadar hematokrit dengan tekanan darah, baik tekanan darah sistolik maupun diastolik. Semakin tinggi kadar hematokrit maka 
semakin tinggi tekanan darah. Didapatkan hubungan bermakna antara kadar hematokrit dan tekanan darah diastolik $(P=0,026)$ sedangkan antara kadar hematokrit dan tekanan darah sistolik tidak bermakna $(P=0,143)$.

Pada perokok kebutuhan oksigen akan meningkat akibat peningkatan karbon monoksida dalam darah yang akan menghambat kinerja hemoglobin, dan terjadi kompensasi berupa pembentukan sel darah merah sehingga akan meningkatkan kadar hematokrit dan hemoglobin yang dapat berpengaruh terhadap viskositas darah serta tahanan perifer. ${ }^{8,9}$ Secara fisiologi peningkatan hematokrit sebesar $10,59 \%$ dan peningkatan viskositas sebesar $20 \%$ dapat menurunkan laju aliran darah sekitar $16,67 \%$ sehingga diperlukan adanya peningkatan tekanan darah sebesar 20\% sebagai mekanisme kompensasi. ${ }^{10}$ Selain itu, nikotin dalam rokok memicu aktivasi sistem saraf simpatis dan melepaskan neurotransmiter yang akan meningkatkan kontraktilitas dan denyut jantung serta aktivasi sistem renin angiotensin aldosteron (RAA) yang menyebabkan peningkatan curah jantung dan tahanan perifer. Peningkatan curah jantung, tahanan perifer dan viskositas darah akan berpengaruh terhadap peningkatan tekanan darah. ${ }^{8,11}$

Penelitian Simone et al. ${ }^{12}$ tentang hubungan tekanan darah dan viskositas darah melaporkan bahwa hematokrit dan Whole Blood Viscosity (WBV) lebih tinggi pada jenis kelamin laki-laki, obesitas sentral, dan perokok. Cirillo et al. ${ }^{7}$ mendapatkan hubungan positif antara hematokrit dan tekanan darah sistolik serta tekanan darah diastolik pada 1.275 laki-laki dan 1.534 perempuoan berusia 25-74 tahun. Berdasarkan hasil studi yang dilakukan oleh Nishikido et al. ${ }^{13}$ pada pekerja lakilaki di Tokyo, Jepang yang berusia antara 18-41 tahun menunjukkan terdapat hubungan positif antara kadar hematokrit dengan tekanan darah sistolik dan tekanan darah diastolik. melalui uji multilple regression didapatkan bahwa hubungan antara kadar hematokrit dan tekanan darah diastolik bermakna dan tidak bergantung pada faktor lain seperti umur, indeks massa tubuh serta kebiasaan konsumsi alkohol, sedangkan hubungan antara kadar hematokrit dan tekanan darah sistolik tidak bermakna.

Skliros et al. ${ }^{14}$ mendapatkan bahwa tekanan darah sistolik dan tekanan darah diastolik berhubungan positif dengan konsumsi alkohol yaitu bila dalam jumlah sedikit menyebabkan dilatasi pembuluh vena perifer dan mengurangi tekanan darah pada orang dengan tekanan darah yang normal. Namun konsumsi alkohol dalam jangka panjang dapat menyebabkan hipertensi atau peningkatan tekanan darah persisten $^{15}$ Usia juga diketahui dapat memengaruhi tekanan darah seseorang. Dengan bertambahnya usia terjadi mekanisme tertentu yang akan berpengaruh terhadap tekanan darah seperti disregulasi sistem RAA, disfungsi ginjal, dan kekakuan pembuluh darah akibat jaringan elastin digantikan jaringan ikat dikarenakan proses degeneratif. Kekakuan pembuluh darah dapat menyebabkan kerusakan baroreflex sehingga terjadi aktivasi sistem saraf simpatis. ${ }^{16}$ Dalam penelitian ini tidak terdapat subyek penelitian yang lanjut usia, sehingga proses degeneratif mungkin belum terjadi. Terdapat beberapa hal yang dapat menimbulkan perbedaan hasil penelitian seperti keragaman subjek penelitian, dilihat dari banyaknya faktor yang dapat memengaruhi tekanan darah seseorang.

\section{SIMPULAN}

Berdasarkan hasil penelitian ini dapat disimpulkan bahwa terdapat hubungan positif namun tidak bermakna antara kadar hematokrit dan tekanan darah sistolik. Terdapat hubungan positif yang bermakna antara kadar hematokrit dan tekanan darah diastolik.

\section{SARAN}

Dapat dilakukan penelitian lebih lanjut tentang viskositas, tekanan darah, dan perokok dalam jumlah sampel yang lebih banyak atau pada populasi, usia dan kriteria lain untuk mendapatkan hasil yang lebih baik.

Bagi penelitian selanjutnya, agar dapat 
menambahkan riwayat konsumsi alkohol pada kriteria eksklusi untuk memperoleh hasil yang lebih akurat dan spesifik.

Bagi perokok dan subyek penelitian, diharapkan mengurangi jumlah konsumsi rokok atau berhenti merokok dikarenakan berbagai macam efek dan penyakit berbahaya yang dapat disebabkan merokok serta dapat mensosialisasikan hal tersebut kepada masyarakat.

\section{DAFTAR PUSTAKA}

1. Salawati T, Amalia R. Perilaku merokok di kalangan mahasiswa Universitas Muhammadiyah Semarang. FKM: UNIMUS;2010.

2. Sirait AM, Pradono Y, Toruan IL. Perilaku merokok di Indonesia. Buletin Penelitian Kesehatan. 2002;30(3):13952.

3. World Health Organization. WHO report on Global Tabacco Epidemic 2008: The MPOWER package. Geneva: World Health Organization, 2008; p.14-5,19.

4. Badan Penelitian dan Pengembangan Kesehatan Kementrian Kesehatan RI. RISKESDAS 2013. Jakarta: Badan Penelitian dan Pengembangan Kesehatan, 2013; p. v, xi-ii, 135

5. Kementrian Kesehatan Republik Indonesia. Infodatin Pusat Data dan Informasi Kementrian Kesehatan RI Hipertensi. 2014. [cited 2017 Aug 4]. Available from: http://www.depkes.go.id/down load.php?file=download/pusdatin/infod atin/infodatin-hipertensi.pdf

6. Letcher RL, Chien S, Pickering TG, Sealey JE, Laragh JH. Direct relationship between blood pressure and blood viscosity in normal and hypertensive subjects. Role of fibrinogen and concentration. Am J Med. 1981;70: 1195-202

7. Cirillo M, Laurenzi M, Trevisan M, Stamler J. Hematocrit, blood pressure, and hypertension. The Gubbio Population
Study. Hypertension. 1992;20:319-26

8. U.S. Departement of Health and Human Services. How tobacco smoke causes disease: The biology and behavioral basis for smoking-atributable disease: a report of the surgeon general. Atlanta, GA: U.S. Departement of Health and Human Services, Centers for Disease Control and Prevention, Office on Smoking and Health, 2010; p. 4, 363-8.

9. Irawati L, Julizar, Irahmah M. Hubungan jumlah dan lamanya merokok dengan viskositas darah. Majalah Kedokteran Andalas. 2011;35(2): 137-46

10. Cinar Y, Demir G, Pac M, Cinar AB. Effect of hematocrit on blood pressure via hyperviscosity. AHJ. 1999;12:739-3.

11. Yogiantoro M. Pendekatan klinis hipertensi. In: Setiati S, Alwi I, Sudoyo AW, Marcellus SK, Setiyohadi B, Syam AF, editors. Buku Ajar Ilmu Penyakit Dalam (6th ed). Jakarta: Interna Publishing, 2014; p. 2261-4.

12. Simone G, Devereux RB, Chinali M, Best LG, Lee ET, Welty TK. Association of blood pressure with blood viscosity in American Indians. Hypertension. 2005;45:625-30

13. Nishikido N, Kobayashi T, Kashiwaaki H. Hematocrit correlates with blood pressure in young male office workers. Industrial Health. 1999;37:76-1

14. Skliros EA, Papadosima SA, Sotiropoulos A, Xipnitos C, Kollias A, Spiliopoulou CA. relationship between alcohol consumption and control of hypertension among elderly Greeks. The Nemea Primary Case Study. Hellenic J Cardiol. 2012;53:26-2

15. Mousa HAL. Effect of alcohol consumption on blood pressure. J Clin Basic Cardiol. 2005;8:75-7

16. Parati G, Ochua JE, Torlasco C, Salvi P, Lambardi C, Bilo G. Aging, high altitude and blood pressure: a complex relationship. High Altitude Medicine \& Biology. 2015;16:97-109 